\title{
Structural studies of cord factors from Mycobacterium simiae related to the capacity for tumour necrosis factor alpha ( $\alpha$-TNF) induction
}

\author{
Correspondence \\ Pedro L. Valero-Guillén \\ plvalero@um.es
}

Received 1 June 2010

Revised 3 August 2010

Accepted 4 August 2010

\author{
Lilian M. Mederos, ${ }^{1}$ Ernesto H. Montoro, ${ }^{1}$ Antonia Bernabéu, ${ }^{2}$ \\ Carlos Linares ${ }^{3}$ and Pedro L. Valero-Guillén ${ }^{3}$
}

${ }^{1}$ Laboratorio Nacional de Referencia e Investigaciones en Tuberculosis y Micobacterias, Centro Colaborador OPS/OMS, Instituto de Medicina Tropical Pedro Kourí (IPK), La Habana, Cuba

${ }^{2}$ Sección de Cultivo de Tejidos, Servicio de Apoyo a la Investigación, Campus Universitario de Espinardo, Universidad de Murcia, Murcia, Spain

${ }^{3}$ Departamento de Genética y Microbiología, Facultad de Medicina y Odontología, Campus Universitario de Espinardo, Universidad de Murcia, Murcia, Spain

\section{INTRODUCTION}

Mycobacterium includes the causative agents of tuberculosis and leprosy, and other saprophytic and opportunistic species, such as Mycobacterium simiae (Falkinham, 1996). The 'habana' group, integrated in this species, was originally isolated in Cuba from patients with pulmonary infections (Valdivia, 1973) and was revealed to be identical to M. simiae serotype I. Although some differences have been noted between ' $h a b a n a$ ' and other strains of M. simiae (Khoo et al., 1996; Mederos et al., 1998, 2007, 2008), the synonymy was clearly established some decades ago (Weiszfeiler \& Karczag, 1976). Interest in the 'habana' group still remains, mainly because some researchers from

Abbreviations: ESI-IT-MS, electrospray ionization-ion trap-MS; ${ }^{1} \mathrm{H}^{13} \mathrm{C}$ $\mathrm{HMBC},{ }^{1} \mathrm{H}-{ }^{13} \mathrm{C}$ heteronuclear multiple bond coherence spectroscopy; ${ }^{1} \mathrm{H}-{ }^{13} \mathrm{C}-\mathrm{HMOC},{ }^{1} \mathrm{H}^{13} \mathrm{C}$ heteronuclear multiple quantum coherence spectroscopy; ${ }^{1} \mathrm{H}-{ }^{1} \mathrm{H}$-COSY, ${ }^{1} \mathrm{H}-{ }^{1} \mathrm{H}$ homonuclear correlated spectroscopy; IL, interleukin; $\alpha-T N F$, tumour necrosis factor alpha.
India demonstrated that 'habana' TMC 5135 presents interesting immunogenic properties in experimental tuberculosis and leprosy (reviewed by Mederos et al., 2006). Moreover, Mederos et al. (2007) have reported that 'habana' TMC 5135 differs from other 'habana' strains and from M. simiae ATCC $25275^{\mathrm{T}}$ in $\alpha$-mycolic acid composition.

Mycolic acids are 2-alkyl-branched, 3-hydroxy long-chain fatty acids (Fig. 1) present in mycobacteria and related micro-organisms. In Mycobacterium, these compounds vary from 60 to 90 carbon atoms, being mainly linked to the arabinogalactan of the cell wall (McNeil et al., 1991). However, they also appear in the cell envelope attached to trehalose, forming the structure of a glycolipid called cord factor (Brennan \& Nikaido, 1995; Daffé \& Draper, 1998). Mycolic acids from Mycobacterium can either contain additional oxygenated functions (as in keto- and methoxymycolates) or not ( $\alpha$ - and $\alpha^{\prime}$-mycolates), and also show variations related to the presence of cis or trans di- 


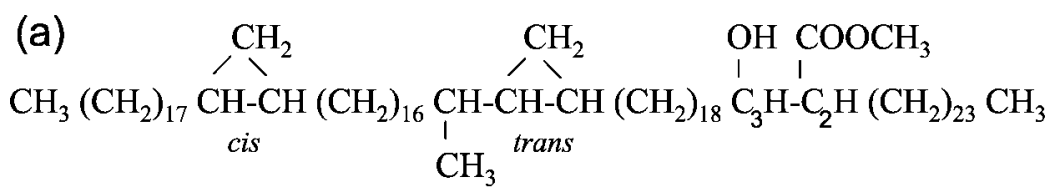

(b)

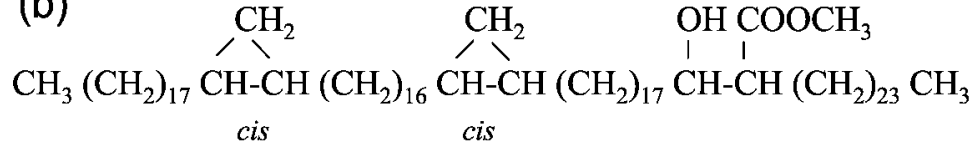

(c)

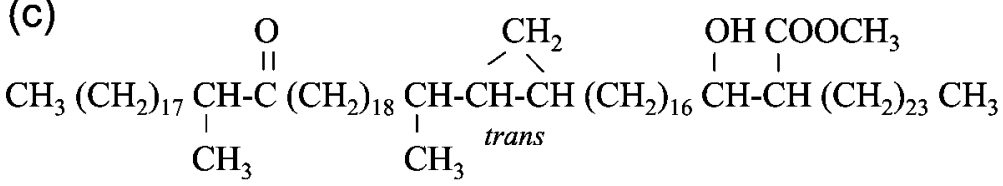

(d)

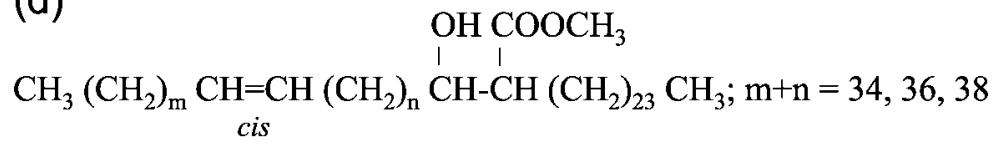

Fig. 1. General structure of major $\alpha-(a, b)$ and keto-mycolates (c) of M. simiae (Mederos et al., 2007) employed to assign the resonances of ${ }^{1} \mathrm{H}-\mathrm{NMR}$ (Fig. 2) and ${ }^{13} \mathrm{C}-\mathrm{NMR}$ (Table 2) spectra. $\alpha$-Mycolates present two 2,3-disubstituted cyclopropane rings, one cis and one trans (a) or two cis (b); ketomycolates mainly have one trans-2,3-disubstituted cyclopropane ring (c). Minor $\alpha$ - and ketomycolates containing one trans double bond instead of one cyclopropane ring are also present in M. simiae (not shown) (Mederos et al., 2007). The structure of $\alpha^{\prime}$-mycolates (C64-C68) is indicated in (d); these compounds only contain one cis double bond (-CH=CH-, Fig. 2). Carbon atoms at positions 2 and 3 of the mycolic acids are indicated in (a); note that $\mathrm{C}-2$ and $\mathrm{C}-3$ are two chiral centres of the molecule with configuration $R / R$ in naturally occurring mycolic acids. substituted cyclopropane rings and unsaturations (Minnikin, 1982; Watanabe et al., 2001).

Cord factor, first detected in Mycobacterium tuberculosis as a toxic substance (Bloch, 1950) and identified as 6,6'dimycoloyl trehalose (see Fig. 2) (Noll et al., 1956), is considered to play an important role in the pathogenesis of tuberculosis (reviewed by Hunter et al., 2006, 2009). Several experimental results have indicated that cord factor is the major molecule secreted by mycobacteria inside macrophages (Rhoades et al., 2003), and that its mycoloyl substituents can influence some aspects of the virulence of M. tuberculosis by modulating the production of some cytokines (Dao et al., 2008; Rao et al., 2005, 2006). Notably, mutants of $M$. tuberculosis altered in the capacity for synthesis of cyclopropane rings show alterations in virulence (Riley, 2006). More precisely, the lack of synthesis of trans-cyclopropane rings gives rise to a hypervirulence phenotype (Rao et al., 2006). Mycolic acids from the delipidated strain 'habana' TMC 5135 contain high amounts of trans-cyclopropane rings (Mederos et al., 2007), leading to the idea that this fact could be reflected in extractable mycolic acid-containing lipids, such as cord factor, and could influence the immunogenicity of the strain. The present work determines the structure of the cord factor of $M$. simiae and reveals some particular characteristics in strain 'habana' TMC 5135, although its capacity to induce tumour necrosis factor alpha $(\alpha-\mathrm{TNF})$ was, in general, similar to that of other strains of the species.

\section{METHODS}

Strains studied. Five strains of $M$. simiae were included in the present study: TMC 5135, ATCC $25275^{\mathrm{T}}$, IPK-220, IPK-337 and IPK342. All of them belonged to the collection of the IPK (Instituto de Medicina Tropical Pedro Kourí), La Habana, Cuba. They were cultivated in liquid UIT-L medium (Mederos et al., 1992) at $35{ }^{\circ} \mathrm{C}$ for 3 weeks, harvested, washed with saline, killed at $120{ }^{\circ} \mathrm{C}$ for $20 \mathrm{~min}$ and dried in a vacuum over $\mathrm{P}_{2} \mathrm{O}_{5}$ (Mederos et al., 2007).

Extraction and purification of cord factor. Cells (2-3 g) were extracted with chloroform/methanol $(1: 1, \mathrm{v} / \mathrm{v})$ and chloroform/ methanol $(2: 1, \mathrm{v} / \mathrm{v})$ (twice) overnight at room temperature with agitation (100 r.p.m.). The extracts were collected and mixed, evaporated to dryness and washed with chloroform/methanol/water $(8: 4: 3$, by vol.). Lipids in the lower phase were collected, evaporated to dryness and precipitated (three times) in methanol $\left(-30{ }^{\circ} \mathrm{C}\right.$, overnight). The resulting insoluble extract (containing cord factor and other lipids) was subjected to silica gel liquid chromatography (particle size $0.040-0.063 \mathrm{~mm}$, Merck), employing methanol in chloroform $(0,2,5,10,30$ and $50 \%)$ as solvent. Fractions were collected and analysed by TLC (silica gel plates, Merck), employing chloroform/methanol $(9: 1, \mathrm{v} / \mathrm{v})$ as solvent. Cord factor was recovered in the $10 \%$ methanol fraction and repurified by preparative TLC (silica gel plates, Merck). In this case, and due to the presence of small amounts of contaminants (apolar glycopeptidolipids), the plates were developed with acetone (three times) followed by chloroform/ methanol $(9: 1, \mathrm{v} / \mathrm{v})$ (once). The purity of cord factor was checked by TLC, as above.

Structural analysis of cord factor. ${ }^{1} \mathrm{H}-\mathrm{NMR}$ and ${ }^{1} \mathrm{H}-{ }^{1} \mathrm{H}$ homonuclear correlated spectroscopy $\left({ }^{1} \mathrm{H}-{ }^{1} \mathrm{H}\right.$-COSY $)$ analyses of cord factor, dissolved $\left(\sim 4 \mathrm{mg} \mathrm{ml}^{-1}\right)$ in deuterochloroform/deuteromethanol $(5: 1, \mathrm{v} / \mathrm{v})$, were carried out in a Brucker instrument $(600 \mathrm{MHz})$ at $298 \mathrm{~K}$. Given the differences initially noted for the chemical shifts of $\mathrm{H}-$ $5 / \mathrm{H}-5^{\prime}$ and $\mathrm{H}-6 \mathrm{~b} / \mathrm{H}-6^{\prime} \mathrm{b}$ among the cord factors of some strains (see Results), and to check for a possible solvent effect, ${ }^{1} \mathrm{H}$-NMR analyses were also done under the same conditions at various ratios $(\mathrm{v} / \mathrm{v})$ of deuterochloroform/deuteromethanol: $30: 1,10: 1$ and $5: 1$, employing cord factor of TMC 5135. This compound, dissolved in deuteropyridine, was also studied by ${ }^{1} \mathrm{H}-\mathrm{NMR}$ and ${ }^{1} \mathrm{H}-{ }^{1} \mathrm{H}-\mathrm{COSY}$, because an influence on chemical shifts related to variations in the configuration of the chiral centres at C-2 and C-3 of mycolates (see Fig. 1) has been noted (Nishizawa et al., 2007). ${ }^{13} \mathrm{C}-\mathrm{NMR}(150 \mathrm{MHz}),{ }^{1} \mathrm{H}_{-}{ }^{13} \mathrm{C}$ heteronuclear multiple quantum coherence spectroscopy $\left({ }^{1} \mathrm{H}-{ }^{13} \mathrm{C}-\mathrm{HMQC}\right)$ and ${ }^{1} \mathrm{H}_{-}{ }^{13} \mathrm{C}$ heteronuclear multiple bond coherence spectroscopy $\left({ }^{1} \mathrm{H}^{13} \mathrm{C}-\mathrm{HMBC}\right)$ experiments were performed with cord factor of TMC 5135 in the above NMR instrument. Both ${ }^{1} \mathrm{H}_{-}{ }^{13} \mathrm{C}-\mathrm{HMQC}$ and 


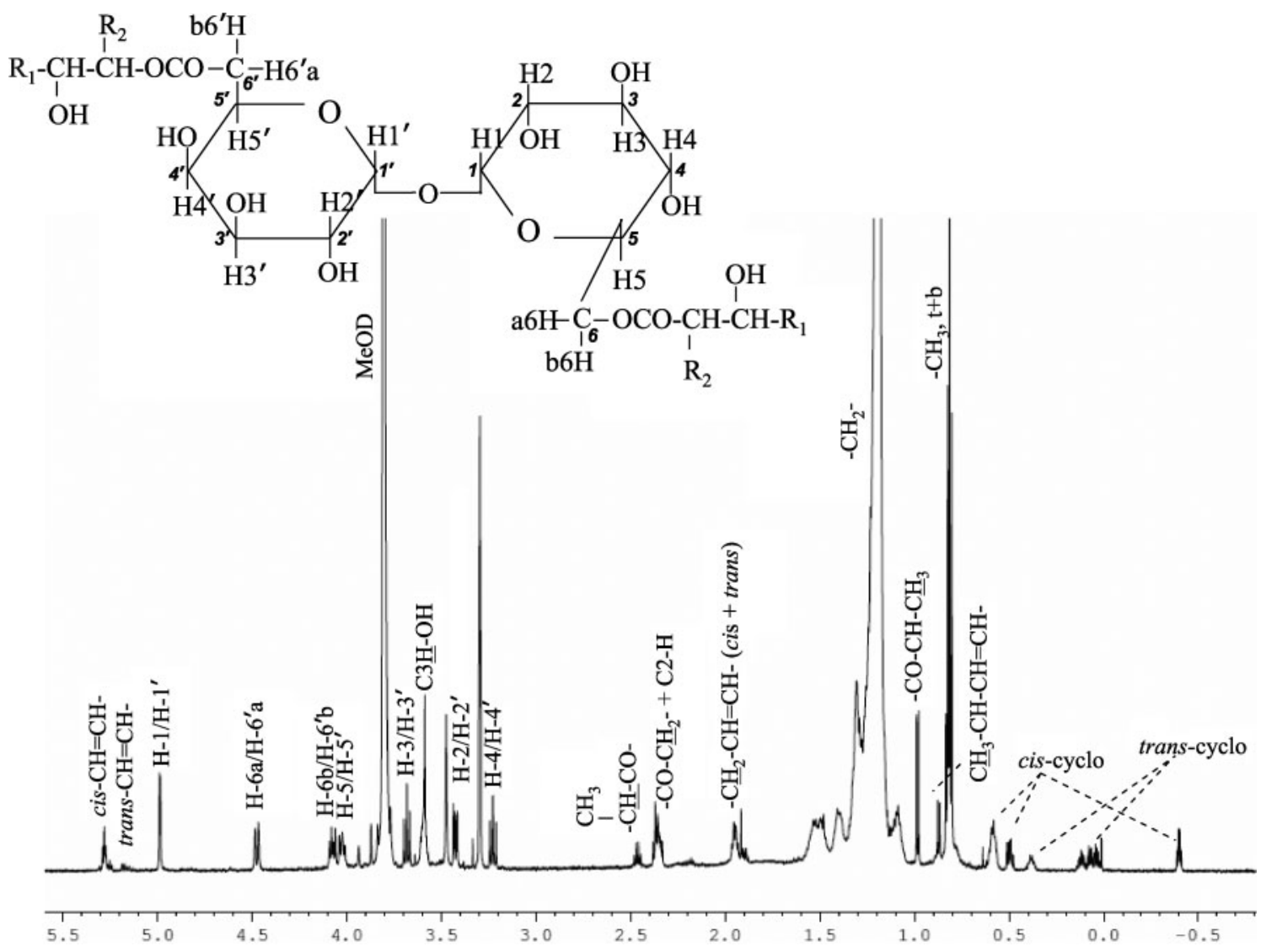

Fig. 2. ${ }^{1} \mathrm{H}-\mathrm{NMR}$ spectrum $(600 \mathrm{MHz}$ in deuterochloroform/deuteromethanol, $5: 1, \mathrm{v} / \mathrm{v}$ ) of cord factor from $M$. simiae ATCC $25275^{\top}$. The general structure of cord factor is included, indicating the protons $\left(\mathrm{H}-1\right.$ to $\mathrm{H}-6$ and $\mathrm{H}-1^{\prime}$ to $\left.\mathrm{H}-6^{\prime}\right)$ and carbons $(1$ to 6 and $1^{\prime}$ to $6^{\prime}$ ). cis-cyclo, cis di-substituted cyclopropane ring; trans-cyclo, trans di-substituted cyclopropane ring. $t$, terminal; b, branched; MeOD, deuteromethanol; cis- $\mathrm{CH}=\mathrm{CH}-\left(\alpha^{\prime}\right.$-mycolates) and trans $-\mathrm{CH}=\mathrm{CH}$ - ( $\alpha$ - and keto-mycolates) are also indicated (see Fig. 1). In some cases the signals correspond to the underlined protons.

${ }^{1} \mathrm{H}-{ }^{13} \mathrm{C}-\mathrm{HMBC}$ served to establish the connectivities between ${ }^{1} \mathrm{H}$ and ${ }^{13} \mathrm{C}$ and, hence, identify the carbons of trehalose and mycoloyl residues of cord factor.

To estimate the relative amounts of the different mycolates, as well as the trans-/cis-cyclopropane ratio, the ${ }^{1} \mathrm{H}-\mathrm{NMR}$ spectra were employed, applying, with slight modifications, some of the formulae proposed by Watanabe et al. (2001). The integrals of the signals at 5.27 p.p.m. (cis double bond: $-\mathrm{CH}=\mathrm{CH}-, 2 \mathrm{H}$, integral/2) (see Results, Fig. 2) and 2.45 p.p.m. (methyne adjacent to a -CO-, 1H) (see Results, Fig. 2) were evaluated for the contribution of, respectively, $\alpha^{\prime}$ - and keto-mycolates. The contribution of $\alpha$-mycolates was calculated from the formula:

$8 \alpha+4 \mathrm{keto}=($ cyclopropane rings $)+($ trans double bond $)+\left(-\mathrm{CH}_{2}-\right.$ adjacent to the trans double bond)

(Note that there are eight and four cyclopropane protons, respectively, for $\alpha$ - and keto-mycolates, and that low amounts of both mycolates contain trans double bonds instead of cyclopropane rings; see Fig. 1.) It was taken into account that the broad signal at 0.58 p.p.m. (3H) (see Results, Fig. 2) includes one proton that does not belong to the cis-cyclopropane ring. The trans-/cis-cyclopropane ratio was deduced from the integrals of the corresponding regions of the spectrum (see Results, Fig. 2). The trans double bonds/ cyclopropane rings ratio was calculated in a similar way.
A small amount of cord factor (1 mg) was saponified overnight at $90{ }^{\circ} \mathrm{C}$ in $15 \%(\mathrm{w} / \mathrm{v}) \mathrm{KOH}$ in methanol, and the liberated mycolic acids were extracted with hexane after acidification of the mixture $\left(20 \% \mathrm{H}_{2} \mathrm{SO}_{4}\right)$ at $\mathrm{pH} 2$. The extract of mycolic acids was washed with distilled water to $\mathrm{pH} 6-7$, dried with anhydrous $\mathrm{Na}_{2} \mathrm{SO}_{4}$, dissolved in chloroform/methanol $(2: 1, \mathrm{v} / \mathrm{v})$ and analysed by electrospray ionization-ion trap-MS (ESI-IT-MS) in negative mode in an MSDIonTrap-VL (Agilent) instrument, with direct infusion of the sample $\left(0.6 \mathrm{ml} \mathrm{h}^{-1}\right)$. The electrospray needle was set at $3.5 \mathrm{kV}$ and compressed $\mathrm{N}_{2}$ employed as the nebulization gas $\left(69 \mathrm{kPa}, 325^{\circ} \mathrm{C}\right)$. The voltage applied was $80 \mathrm{~V}$. Spectra were recorded over the mass range $m / z 100-2000$ at 3-5 s. Monoisotopic masses (obtained from the empiric formulae at ChemCalc; http://www.chemcalc.org) and previous data (Mederos et al., 2007) served as a reference for identification of mycolic acids. For comparative purposes, mycolic acids from delipidated cells $(50 \mathrm{mg})$ were also studied in a similar way. Both cord factor and delipidated cells from TMC 5135 were analysed in duplicate (independent analyses).

$\boldsymbol{\alpha}$-TNF response of RAW $\mathbf{2 6 4 . 7}$ cells to cord factor. The method described by Rao et al. (2006) was followed with some modifications. Cord factor was resuspended by sonication in 2-propanol (Merck) $\left(1 \mathrm{mg} \mathrm{ml}^{-1}\right)$ and layered [0 $\mu \mathrm{g}$ (2-propanol alone), 0.1, 1 and $10 \mu \mathrm{g}$ ] in 24-well tissue culture plates (Nunc). RAW 264.7 cells (mouse 


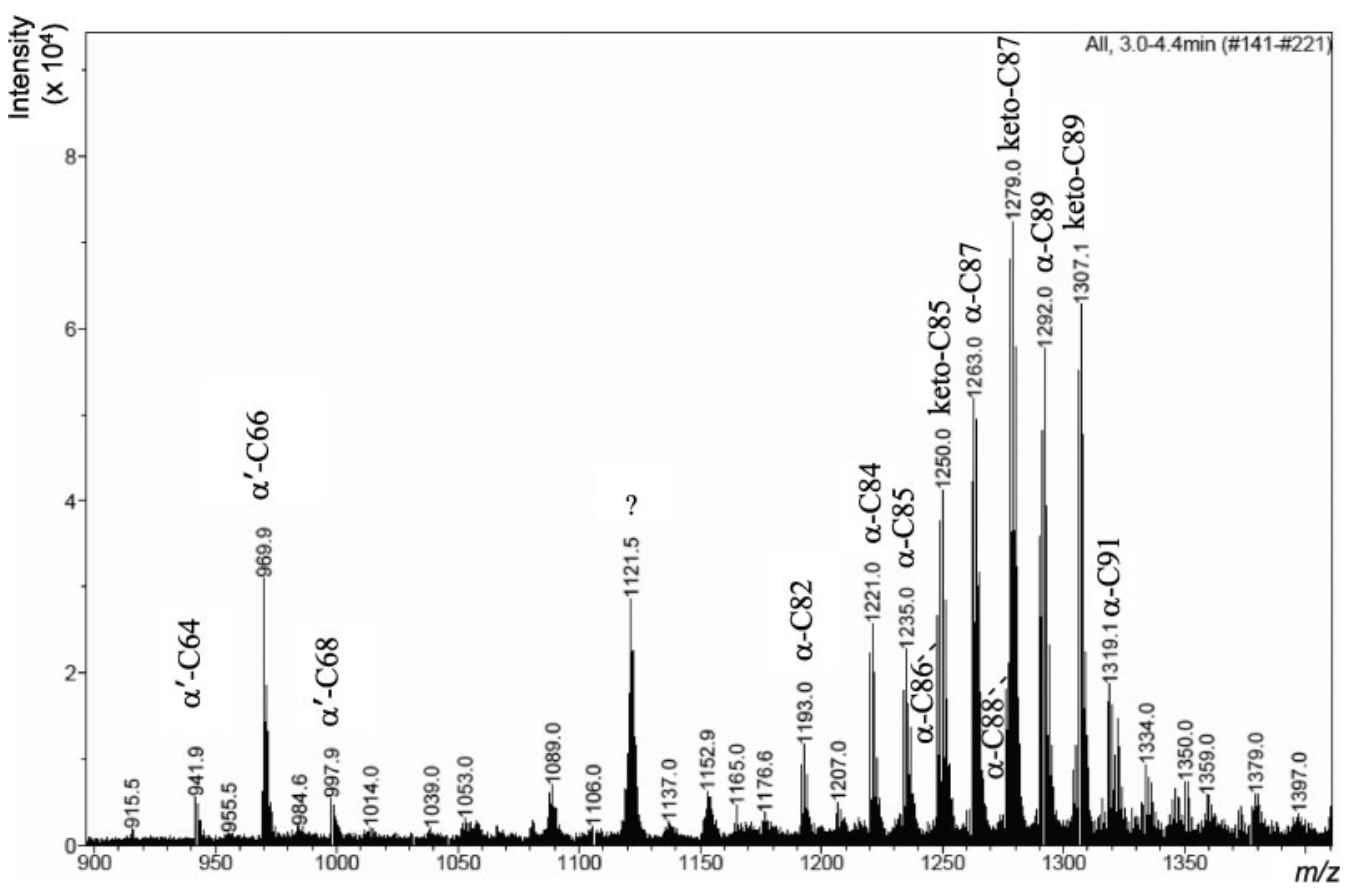

Fig. 3. ESI-IT-MS spectrum of mycolic acids from cord factor of $M$. simiae 'habana' TMC 5135. The different structural types $\left(\alpha^{\prime}-, \alpha\right.$ - and keto-mycolates) are indicated, together with the chain length. The $m / z$ values correspond to the $(M-H)^{-1}$ ions $($ see Table 4). ?, Contaminant from adsorbant.

leukaemia macrophage cell line, purchased from ATCC) were added ( $10^{6}$ cells) in $500 \mu \mathrm{l}$ Dulbecco's Modified Eagle's Medium (DMEM) (high glucose), supplemented with $10 \%$ fetal calf serum, penicillin $\left(100 \mathrm{U} \mathrm{ml}^{-1}\right)$ and streptomycin $\left(100 \mu \mathrm{g} \mathrm{ml}^{-1}\right)$, and incubated at $37{ }^{\circ} \mathrm{C}$ in $5 \% \mathrm{CO}_{2}$ for $24 \mathrm{~h}$. All cultures were negative for mycoplasma and LPS. Supernatants were collected, centrifuged and kept at $-30{ }^{\circ} \mathrm{C}$ until analysis. The amount of $\alpha$-TNF was analysed using the BD OptEIA mouse $\alpha$-TNF kit (BD Bioscience), following the recommendations of the manufacturer. The analyses were done in duplicate experiments (and duplicated assays), and general statistical differences (significance at $P<0.05$ ) were estimated by two-way analyses of variance (SPSS 15.0) and the least significant difference test.

\section{RESULTS}

\section{Structure of cord factor}

Cord factor from $M$. simiae strains was unambiguously identified as 6,6 $6^{\prime}$-dimycoloyl trehalose by ${ }^{1} \mathrm{H}-\mathrm{NMR},{ }^{1} \mathrm{H}-{ }^{1} \mathrm{H}-$ COSY-NMR, ${ }^{13} \mathrm{C}-\mathrm{NMR},{ }^{1} \mathrm{H}_{-}-{ }^{13} \mathrm{C}-\mathrm{HMQC}$ and ${ }^{1} \mathrm{H}_{-}{ }^{13} \mathrm{C}-$ HMBC. The ${ }^{1} \mathrm{H}-\mathrm{NMR}$ spectra obtained (Fig. 2) were in general agreement with those reported in the literature for natural and synthetic cord factors (Niescher et al., 2006; Nishizawa et al., 2007). The anomeric protons of trehalose $\left(\mathrm{H}-1 / \mathrm{H}_{-1}{ }^{\prime}\right)$ (Fig. 2) resonated at 4.98 p.p.m., and $\mathrm{J}_{1,2}$ was $3.9 \mathrm{~Hz}$, demonstrating an $\alpha, \alpha^{\prime}$ configuration (Lin et al., 2007). Moreover, two of the H-6 (H-6a/H-6'a) appeared at 4.50 p.p.m. and the two remaining $\left(\mathrm{H}-6 \mathrm{~b} / \mathrm{H}-6^{\prime} \mathrm{b}\right)$ at 4.08 p.p.m., indicating that the C-6 hydroxyl groups (C-6/ C-6') were esterified (Lin et al., 2007). Unexpectedly, the signals of $\mathrm{H}-5 / \mathrm{H}-5^{\prime}$ and $\mathrm{H}-6 \mathrm{~b} / \mathrm{H}-6^{\prime} \mathrm{b}$ of trehalose from cord factor of the strains 'habana' TMC 5135 and IPK-220 overlapped at 4.05 p.p.m. (results not shown), although this fact was attributed to a solvent effect (see below). $\mathrm{H}-2 / \mathrm{H}-2^{\prime}$, $\mathrm{H}-3 / \mathrm{H}-3^{\prime}, \mathrm{H}-4 / \mathrm{H}-4^{\prime}$ and $\mathrm{H}-5 / \mathrm{H}-5^{\prime}$ (Fig. 2) resonated at, respectively, 3.42, 3.67, 3.22 and 4.02 p.p.m. The spectrum of strain IPK-220 showed reverse chemical shifts for H-5/ $\mathrm{H} 5^{\prime}$ and $\mathrm{H}-6 \mathrm{~b} / \mathrm{H}-6^{\prime} \mathrm{b}$ (results not shown). On the other hand, $\mathrm{H}-3 / \mathrm{H}-3^{\prime}$ from cord factor of TMC 5135 overlapped with the signal of deuteromethanol (results not shown).

To check the apparent anomalies noted in the ${ }^{1} \mathrm{H}-\mathrm{NMR}$ spectra of TMC 5135 and IPK-220, cord factor of the first strain was reanalysed employing the following ratios $(\mathrm{v} / \mathrm{v})$ of deuterochloroform/deuteromethanol: $30: 1,10: 1$ and $5: 1$. The results are presented in Table 1 , and prove that the chemical shifts of $\mathrm{H}-5 / \mathrm{H}^{\prime}$ and $\mathrm{H}-6 / \mathrm{H}^{\prime}$ were the most influenced; thus, the overlap mentioned above was attributed to a solvent effect and no anomalies were actually considered to be present in the spectra. Moreover, when using deuteropyridine as solvent, the ${ }^{1} \mathrm{H}-\mathrm{NMR}$ spectrum of cord factor from TMC 5135 (not shown) (H-1/H1', 5.63 p.p.m.; H-2/H-2', 4.00 p.p.m.; H-3/H-3', 4.46 p.p.m.; H-4/H-4', 3.92 p.p.m.; $\mathrm{H}-5 / \mathrm{H} 5^{\prime}$ and $\mathrm{H}-6 \mathrm{a} / \mathrm{H} 6^{\prime}$ a, 4.92 p.p.m.; H-6b/H6'b, 4.46 p.p.m.) did not differ from those reported by Nishizawa et al. (2007) for compounds presenting a $2 R, 3 R /$ $2^{\prime} R, 3^{\prime} R$ configuration. On the other hand, the ${ }^{13} \mathrm{C}-\mathrm{NMR}$ spectrum of cord factor from TMC 5135 (Table 2) was similar to those of other cord factors reported in the literature (Nishizawa et al., 2007). 
Table 1. Chemical shifts (p.p.m.) ( ${ }^{1} \mathrm{H}-\mathrm{NMR}$ ) of the trehalose protons of cord factor (see Fig. 2) from M. simiae ('habana') TMC 5135 at various deuterochloroform/deuteromethanol ratios

$-\mathrm{CH}=\mathrm{CH}-$ was included as a reference.

\begin{tabular}{|lcccc|}
\hline Proton & \multicolumn{4}{c|}{ Deuterochloroform/deuteromethanol ratio (v/v) } \\
\cline { 2 - 5 } & $\mathbf{3 0 : 1}$ & $\mathbf{1 0 : 1}$ & $\mathbf{5 : \mathbf { 1 } ^ { * }}$ & $\mathbf{5 : \mathbf { 1 } \dagger}$ \\
\hline $\mathrm{H}-1 / \mathrm{H}^{\star} \mathbf{1}^{\prime}$ & 4.92 & 4.95 & 4.96 & 4.98 \\
$\mathrm{H}-2 / \mathrm{H}-2^{\prime}$ & 3.47 & 3.43 & 3.42 & 3.42 \\
$\mathrm{H}-3 / \mathrm{H}-3^{\prime}$ & 3.71 & 3.69 & 3.68 & $\ddagger$ \\
$\mathrm{H}-4 / \mathrm{H}-4^{\prime}$ & 3.14 & 3.18 & 3.20 & 3.22 \\
$\mathrm{H}-5 / \mathrm{H}-5^{\prime}$ & 4.29 & 4.16 & 4.08 & 4.05 \\
$\mathrm{H}-6 \mathrm{a} / \mathrm{H}-6^{\prime} \mathrm{a}$ & 4.73 & 4.60 & 4.52 & 4.50 \\
$\mathrm{H}-6 \mathrm{~b} / \mathrm{H}-6^{\prime} \mathrm{b}$ & 3.80 & 3.94 & 4.01 & 4.05 \\
$-\mathrm{CH}=\mathrm{CH}-$ & 5.27 & 5.27 & 5.27 & 5.27 \\
\hline
\end{tabular}

${ }^{\star}$ Second analysis.

$\dagger$ First analysis.

‡Overlaps with deuteromethanol.

Acyl substituents were identified as $\alpha^{\prime}$-mycoloyl (signal at 5.27 p.p.m., due to a cis double bond, $-\mathrm{CH}=\mathrm{CH}-), \alpha-$ mycoloyl (signals at $-0.40,0.49$ and 0.58 p.p.m., due to a cis di-substituted cyclopropane ring) and keto-mycoloyl (signals at 0.98 and 2.45 p.p.m., due to, respectively, a methyl branch and a methyne adjacent to the $-\mathrm{C}=\mathrm{O}$ )

Table 2. ${ }^{13} \mathrm{C}-\mathrm{NMR}$ analysis of cord factor from M. simiae ('habana') TMC 5135 (see Figs 1 and 2 for reference)

Chemical shifts are given in p.p.m. (in some cases they correspond to the underlined carbons). The different carbons were attributed by means of ${ }^{1} \mathrm{H}_{-}{ }^{13} \mathrm{C}-\mathrm{HMQC}$ and ${ }^{1} \mathrm{H}_{-}{ }^{13} \mathrm{C}-\mathrm{HMBC}$ experiments.

\begin{tabular}{|c|c|}
\hline${ }^{13} \mathrm{C}$ & Chemical shift \\
\hline \multicolumn{2}{|l|}{ Trehalose } \\
\hline $\mathrm{C} 1 / \mathrm{C} 1^{\prime}$ & 94.44 \\
\hline $\mathrm{C} 2 / \mathrm{C} 2^{\prime}$ & 71.33 \\
\hline $\mathrm{C} 3 / \mathrm{C}^{\prime}$ & 72.75 \\
\hline $\mathrm{C} 4 / \mathrm{C} 4^{\prime}$ & 70.92 \\
\hline $\mathrm{C} 5 / \mathrm{C}^{\prime}$ & 69.88 \\
\hline $\mathrm{C} 6 / \mathrm{C}^{\prime}$ & 63.87 \\
\hline \multicolumn{2}{|l|}{ Mycoloyl substituents } \\
\hline -CO- (keto-mycolates), - ${ }^{1} \mathrm{COO}-$ & 175.35 \\
\hline$-\mathrm{CH}=\mathrm{CH}-($ cis $) \alpha^{\prime}$-mycolates & 129.76 \\
\hline${ }^{3} \mathrm{C}$ & 72.46 \\
\hline${ }^{2} \mathrm{C}$ & 52.43 \\
\hline trans-Cyclopropane & $10.32,19.50,25,19$ \\
\hline cis-Cyclopropane & $10.72,15.64$ \\
\hline$-\mathrm{CH}_{3}$ & 13.87 \\
\hline $\mathrm{CH}_{3}-\mathrm{CH}-\mathrm{CO}-$ & 16.12 \\
\hline$\overline{\mathrm{C}} \mathrm{H}_{3}-\underline{\mathrm{CH}}-\mathrm{CO}-$ & 46.23 \\
\hline$-\mathrm{CH}_{2}-\mathrm{CO}-$ & 41.08 \\
\hline$\overline{\mathrm{CH}}_{3}-\mathrm{CH}$-trans-cyclopropane & 37.29 \\
\hline $\mathrm{CH}_{3}-\mathrm{CH}$-trans-cyclopropane & 18.49 \\
\hline$-\mathrm{CH}_{2-}$ & $22.53-34.69$ \\
\hline
\end{tabular}

(Fig. 2) (Mederos et al., 2007; Watanabe et al., 1999). Other signals related to a trans di-substituted cyclopropane ring (0.04-0.07 p.p.m.) (due to $\alpha$ - and keto-mycoloyl substituents), $-\mathrm{CH}_{2}$ - and $-\mathrm{CH}_{3}$ (terminal and branched) were also present in the spectra (Fig. 2), as were those related to the presence of trans double bonds (doublet at 0.87 p.p.m., $\mathrm{CH}_{3}-\mathrm{CH}-\mathrm{CH}=\mathrm{CH}-$; and multiplets at 5.17 and 5.23 p.p.m., trans- $\mathrm{CH}=\mathrm{CH}-$ ) (Fig. 2) (Mederos et al. 2007; Watanabe et al., 1999). Details of the ${ }^{13} \mathrm{C}-\mathrm{NMR}$ spectrum of the cord factor from TMC 5135 (Table 2) supported the data from the ${ }^{1} \mathrm{H}-\mathrm{NMR}$, and were in agreement with earlier reports (Nishizawa et al., 2007), including those for different types of mycolates (Schroeder \& Barry, 2001; Watanabe et al., 1999).

The overall mycolic acid composition of cord factor from M. simiae was estimated from the ${ }^{1} \mathrm{H}-\mathrm{NMR}$ spectra and is shown in Table 3. Notably, the data suggested the existence of high proportions of keto-mycolates in TMC 5135 and ATCC $25275^{\mathrm{T}}$, the strains with the most elevated trans-/ciscyclopropane ratios (Table 3). $\alpha^{\prime}$-Mycolates were abundant in all strains except TMC 5135; on the other hand, the amounts of trans-unsaturated $\alpha$ - and keto-mycolates varied among strains and seemed to be particularly prominent in the case of ATCC $25275^{\mathrm{T}}$ (Table 3). ESI-IT-MS (Fig. 3, Table 4), confirmed the general evidence obtained by ${ }^{1} \mathrm{H}-$ NMR regarding the mycolic acid composition of cord factor in the strains studied. Thus, $\alpha^{\prime}-(\mathrm{C} 64-\mathrm{C} 68), \alpha-(\mathrm{C} 80-$ C91) and keto- (C85-C91) mycolates were identified in the mass spectra (Fig. 3). According to previous findings with M. simiae (Mederos et al., 2007) and other mycobacteria (Minnikin, 1982; Watanabe et al., 2001), the odd carbon number $\alpha$-mycolate series (Fig. 1a) mainly contains one trans di-substituted cyclopropane ring plus one cis disubstituted cyclopropane ring, whereas the even carbon number series (Fig. 1b) has two cis di-substituted cyclopropane rings. On the other hand, the odd carbon 
Table 3. Whole mycolic acid composition of cord factors from different strains of $M$. simiae as deduced from the ${ }^{1} \mathrm{H}-\mathrm{NMR}$ spectra (see Methods)

\begin{tabular}{|lccc|}
\hline Strain & $\boldsymbol{\alpha} / \boldsymbol{\alpha}^{\prime} /$ keto & $\begin{array}{c}\text { trans-Cyclopropane/ } \\
\text { cis-cyclopropane }\end{array}$ & $\begin{array}{c}\text { trans double bond/ } \\
\text { cyclopropane }\end{array}$ \\
\hline TMC 5135 & $1 / 0.47 / 1.16$ & 0.72 & 0.25 \\
ATCC 25275 & $1 / 0.68 / 1.37$ & 0.73 & 0.41 \\
IPK-220 & $1 / 0.87 / 0.59$ & 0.62 & 0.37 \\
IPK-337 & $1 / 0.72 / 0.67$ & 0.66 & 0.28 \\
IPK-342 & $1 / 0.66 / 0.85$ & 0.60 & 0.19 \\
\hline
\end{tabular}

number keto-mycolate series (Fig. 1c) showed one trans disubstituted cyclopropane ring. It should be noted, however, that the even carbon number series of $\alpha$ - and ketomycolates can have a trans double bond instead of a cyclopropane (Mederos et al., 2007; Watanabe et al., 2001). Taking into account the intensities of the different $(\mathrm{M}-\mathrm{H})^{-1} / z$ ions among the $\alpha^{\prime}$-mycolate series, C66:1 was always more abundant, as was C87 in the case of keto-mycolates (Table 4). Nevertheless, differences were detected for $\alpha$-mycolates, because the odd carbon number series (particularly C87 and C89) predominated in TMC 5135, whereas more equal levels of the odd and even carbon number series were found for ATCC $25275^{\mathrm{T}}$, IPK220, IPK-337 and IPK-342 (Table 4). The general patterns of mycolic acids from delipidated cells were similar to those of cord factors (Table 4). It should be noted that TMC 5135 seems to maintain the same levels of odd and even carbon number $\alpha$-mycolate series in both cord factor and delipidated cells (57.4 vs $55.3 \%$ ) (Table 4 ), whereas in the remaining strains the content of the odd carbon number $\alpha$-mycolate series was higher in the cord factor than in delipidated cells (45.6-48.4 vs 33.6-37.2\%) (Table 4).

\section{Induction of $\alpha$-TNF}

Cord factor from strains ATCC $25275^{\mathrm{T}}$, IPK-342 and TMC 5135 was able to induce the production of $\alpha$-TNF in RAW 264.7 cells at all assayed concentrations. The results indicated that $\alpha$-TNF levels increased slightly with the amount of cord factor in the cases of TMC 5135 and IPK342. As depicted in Table 5, significant statistical differences were noted among strains at $0.1 \mu \mathrm{g}$ and at $1.0 \mu \mathrm{g}$ cord factor, but not at $10 \mu \mathrm{g}$. However, overall, the induction of $\alpha$-TNF could be considered similar for the three compounds examined.

\section{DISCUSSION}

Data from the present study reveal the existence of cord factor in all M. simiae strains studied. The identification of cord factor was achieved by a combination of several techniques; however, the initial results from ${ }^{1} \mathrm{H}-\mathrm{NMR}$ were rather unexpected, because of the overlap of $\mathrm{H}-5 / \mathrm{H}-5^{\prime}$ and $\mathrm{H}-6 \mathrm{~b} / \mathrm{H6}^{\prime} \mathrm{b}$ in TMC 5135 and IPK-220, which was not found in strains ATCC $25275^{\mathrm{T}}$, IPK-337 and IPK-342. Our findings suggest that such overlapping can be explained by a solvent effect (Table 1). Naturally occurring mycolic acids so far examined are $2 R, 3 R$ (see for example Quémard et al., 1997); congruent with this fact, the ${ }^{1} \mathrm{H}-\mathrm{NMR}$ spectrum obtained when using deuteropyridine as solvent also favours the hypothesis that mycolic acids of $M$. simiae present the same configuration at these chiral centres. However, as NMR analyses were performed on mixtures of cord factor subtypes, the peculiarity observed could be due to the mycolate composition of the different cord factors. Indeed cord factor of TMC 5135 has been shown to contain a specific combination of mycolic acids in which the odd carbon number series (i.e. trans-cyclopropanes) and keto-mycolates prevail. It has been demonstrated that these decorations on the long mero mycolic chain induce conformational modifications on the long mero chain (Villeneuve et al., 2007, 2010). Such conformational changes of mycolic acids could under certain conditions give a different NMR spectrum.

The whole-lipid composition of cord factor in the strains studied was qualitatively similar, and characterized by the presence of $\alpha^{\prime}-, \alpha$ - and keto-mycolates. Thus, six basic combinations of mycolic acids in cord factor can be predicted, and due to the wide variations in the chain length of the individual mycolates (see Table 4), numerous possible molecular species may exist, as already evidenced for cord factors of M. tuberculosis and other species of the genus (Fujita et al., 2005).

As indicated above, a specific combination of $\alpha$-mycoloyl substituents was found for TMC 5135, in which the odd carbon number series prevailed, unlike other strains, which tended to contain more elevated levels of the even carbon number $\alpha$-mycoloyl series in their cord factors. Mycolic acids from delipidated cells were, as expected, similar to those found in cord factor, although, again, the same differences with respect to the $\alpha$-mycolates were detected between TMC 5135 and the other strains examined. Other different characteristics among strains are related to ketoand $\alpha^{\prime}$-mycolates, and also to the trans-/cis-cyclopropane ratio, although no additional distinctive features of TMC 5135 were found. Variations in the fine structure of mycolic acids within strains of a given species have also been reported in Mycobacterium (see for example Minnikin, 1982; Watanabe et al., 2001, 2002), although their biological significance is uncertain. 
Table 4. Mycolic acid composition of cord factor and delipidated cells of several strains of M. simiae

Relative percentages within each series (referred to $100 \%$ ) were calculated directly from the intensities of the different ions $(\mathrm{M}-\mathrm{H})^{-1}$ obtained by ESI-TRAP-MS. For a given strain, the MS spectrum consisted of at least 50 scans. Values for TMC 5135 are the mean \pm SD of two independent analyses. $(\mathrm{M}-\mathrm{H})^{-1}$ values are given with a maximum error of 800 p.p.m. for $\alpha$ - and ketomycolates.

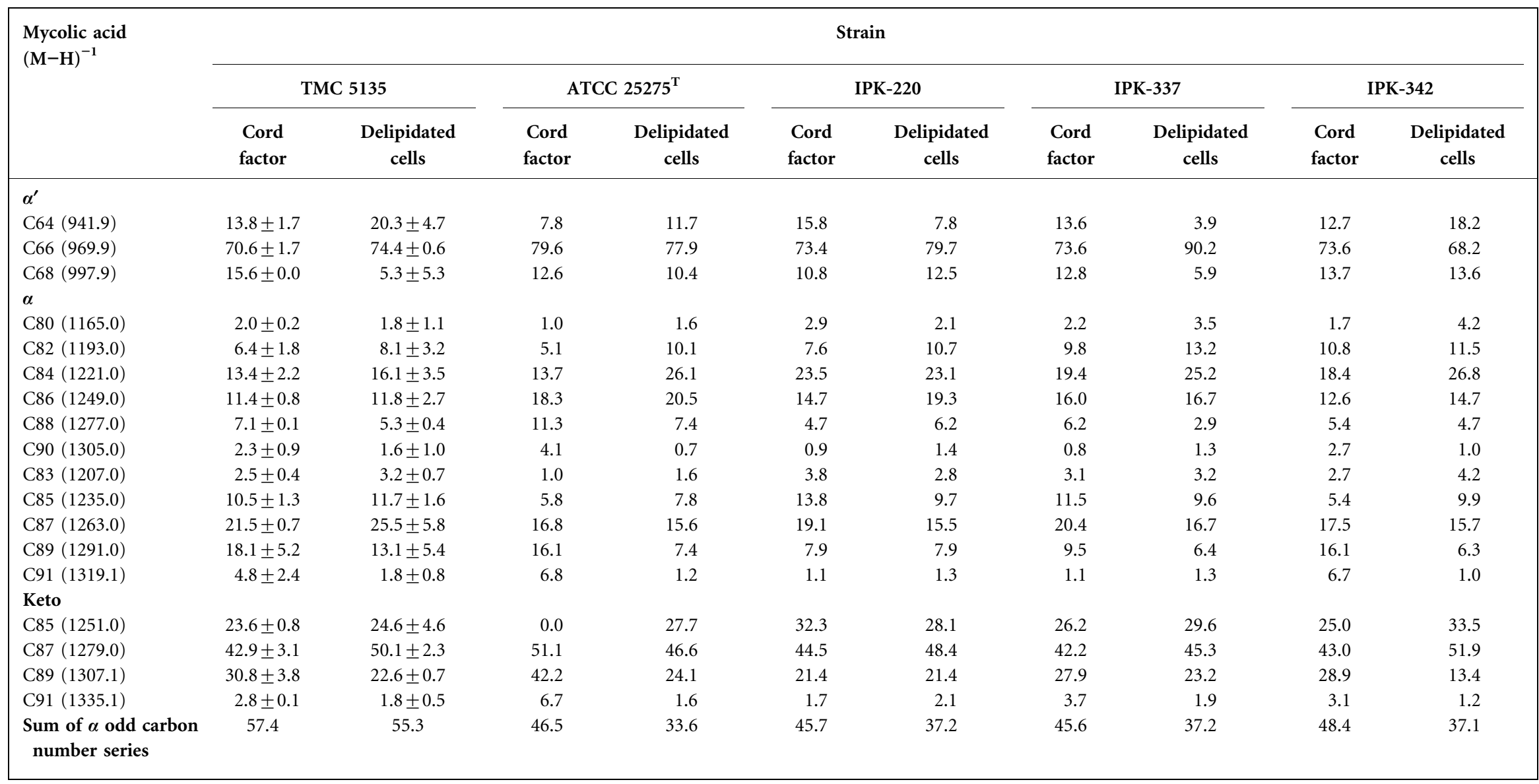


Table 5. Induction of $\alpha$-TNF (pg ml ${ }^{-1}$ ) in RAW 264.7 cells by cord factor from several strains of M. simiae

The results are expressed as a mean $\pm \mathrm{SD}$ of two experiments done in duplicate.

\begin{tabular}{|lcccc|}
\hline Strain & \multicolumn{4}{c|}{ Amount of cord factor $(\boldsymbol{\mu g})$} \\
\cline { 2 - 5 } & $\mathbf{0}^{*}$ & $\mathbf{0 . 1} \dagger$ & $\mathbf{1 \neq}$ & 195 \\
\hline TMC 5135 & $1273.6 \pm 179.3$ & $1901.4 \pm 25.7$ & $1922.5 \pm 55.6$ & $1937.6 \pm 28.3$ \\
ATCC 25275 & $1273.6 \pm 179.3$ & $2049.0 \pm 21.0$ & $1952.1 \pm 26.3$ & $2000.0 \pm 47.7$ \\
IPK-342 & $1273.6 \pm 179.3$ & $1755.7 \pm 80.3$ & $1827.1 \pm 7.8$ & $1917.3 \pm 29.8$ \\
\hline
\end{tabular}

${ }^{*}$ A single control was done in the same plate for the three strains.

$\dagger$ Significant statistical differences between TMC 5135/ATCC $25275^{\mathrm{T}}(P<0.01)$, TMC 5135/IPK-342 $(P<0.001)$ and ATCC $25275^{\mathrm{T}} / \mathrm{IPK}-342$ $(P<0.001)$.

¥Significant statistical differences between TMC 5135/IPK-342 $(P<0.05)$ and ATCC $25275^{\mathrm{T}} /$ IPK-342 $(P<0.002)$.

$\$$ No significant statistical differences were found among strains.

An initial approach to the analysis of the biological activity of cord factor of TMC 5135 was made by studying its capacity for induction of $\alpha$-TNF, in an attempt to explain part of the immunogenicity reported for this strain (Mederos et al., 2006). The results obtained, however, do not allow us to attribute a special meaning to this molecule, in spite of its particular fine structure, since cord factors from ATCC $25275^{\mathrm{T}}$ and IPK-342 were able to induce similar levels of $\alpha$-TNF in RAW 264.7 cells. It has been reported that cord factors from non-pathogenic mycobacteria show granulomatogenic properties (Fujita et al., 2007), and that, in general, this particular activity should operate in an $\alpha$-TNF-dependent way (Takimoto et al., 2006; Welsh et al., 2008). Differences in toxicity and granulomatogenic activity found for the cord factors of various species of mycobacteria have been related to the chain length of $\alpha$-mycolates (Fujita et al., 2007). Also, various Mycobacterium bovis Bacillus Calmette-Guérin (BCG) strains (and cord factors isolated from them), differing in methoxy-mycolate content, vary in their capacity to induce several cytokines, including $\alpha$-TNF (Hayashi et al., 2009). The relationships of mycolic acids to biological activities are also linked to both cyclopropanation (Glickman et al., 2000; Rao et al., 2005, 2006) and oxygenation (Bhatt et al., 2007; Dao et al., 2008; Dubnau et al., 2000). At present, it is difficult to determine the exact way by which these effects operate, although they probably rely on complex mechanisms of recognition of cord factor in which both trehalose and mycoloyl substituents seem to play a role (Bowdish et al., 2009; Ishikawa et al., 2009; Ozeki et al., 2006; Werninghaus et al., 2009).

Cyclopropanation of mycolic acids has been reported to be critical for the biological activity of cord factor of $M$. tuberculosis and to have a strong influence on several aspects of the virulence of that species (Rao et al., 2005, 2006; Riley, 2006). No data are available for $\alpha^{\prime}$-mycolates in this context. These compounds, shorter than $\alpha$ - and oxygenated mycolates and with one cis double bond, are roughly equivalent to those found in Nocardia and Rhodococcus (Minnikin \& Goodfellow, 1976), whose cord factors, being granulomatogenic, may have low toxicity (Ueda et al., 2001) or even produce cachexia (Silva et al., 1988). From the present study, it is unclear how the differences in both cyclopropanation and cis unsaturation noted among the strains can affect the different levels of induction of $\alpha$-TNF, in spite of the significant statistical differences noted. Overall, the relationship of this finding to the structural details of the respective cord factors is unclear and may merely represent an experimental artefact.

Irrespective of differences in methodology among different reports, the levels of induction of $\alpha$-TNF by cord factor from $M$. simiae appear lower than those published for cord factor from wild strains of M. tuberculosis (Dao et al., 2008; Rao et al., 2005, 2006), although significantly higher than those from BCG strains and non-pathogenic mycobacteria (Mycobacterium phlei) (Hayashi et al., 2009). $\alpha$-Mycolic acids from $M$. tuberculosis are essentially cis-cyclopropanated (Minnikin, 1982; Watanabe et al., 2001). However, the low amounts of trans derivatives present in this species seem to play an important role in the virulence properties of this micro-organism, because the deletion of the cmaA2 gene, responsible for the synthesis of the proximal trans-cyclopropane in keto- and methoxy-mycolates (see Takayama et al., 2005), produces a hypervirulence phenotype (Rao et al., 2006), characterized by a high induction of $\alpha$-TNF. Nevertheless, the mmaA4 mutant, devoid of oxygenated mycolic acids (see Takayama et al., 2005), also induces high levels of $\alpha$-TNF and interleukin (IL)-12, and shows reduced virulence (Dao et al., 2008). Other factors, such as proximal cis-cyclopropanation in $\alpha$ mycolic acids, also influence the capacity of the $M$. tuberculosis cord factor to induce the above-mentioned cytokine (Rao et al., 2005).

Strain 'habana' TMC 5135 is considered immunogenic in experimental tuberculosis (Gupta et al., 1979) and leprosy (Singh et al., 1989, 1997), producing in both cases delayedtype hypersensitivity and lymphostimulatory responses. Several attempts have been made to define the antigens responsible for immunoprotection. In this context it has 
been found that secretory proteins from 30 to $60 \mathrm{kDa}$ induce IL-2, IL-12 and interferon gamma in macrophages from vaccinated mice (Divya Jyothi et al., 2000). These molecules, together with others such as $\alpha$-TNF, are important effectors in the immunology of tuberculosis (Cooper, 2009; Dietrich \& Doherty, 2009). Because the induction of this cytokine can be achieved by the cord factor of TMC 5135, it could be argued that this molecule should play some role in the immunoprotection against experimental tuberculosis and leprosy observed by several authors (reviewed by Mederos et al., 2006). It remains open to further analysis whether cord factor from TMC 5135 also has a role in the induction of other immunomodulatory proteins (e.g. IL-2 and IL-12).

\section{NOTE ADDED IN PROOF}

Part of this paper was presented as a poster at the 41st World Conference on Lung Health of the International Union against Tuberculosis and Lung Disease (The Union), Berlin, 11-15 November, 2010. An abstract of this poster will be published: Mederos, L. M., Montoro, E., Bernabeu, A., Martínez, D. \& Valero-Guillen, P. L. (2010). Cord-factor of M. simiae: strain Habana TMC 5135, considered immunogenic in experimental tuberculosis and leprosy, presents some particular characteristics and is able to induce the secretion of $\alpha$-TNF in RAW 264.7 cells. Int J Tuberc Lung Dis 14, S241.

\section{ACKNOWLEDGEMENTS}

This work was supported by the Ministerio de Ciencia e Innovación, Spain, and the European Union, FEDER (contract PI080079), and by IPK (Instituto de Medicina Tropical Pedro Kourí), La Habana, Cuba. Dr A. de Godos and D. Martínez [Experimental Science Support Service (Servicio de Apoyo a la Investigación; SAI), University of Murcia] are acknowledged for NMR analyses. We are also indebted to J. Rodríguez (SAI, University of Murcia) for MS analyses. Statistical analyses were done with the advice of Dr M. Canteras (Statistics, Faculty of Medicine, University of Murcia). Dr M. Gacto (Department of Genetics and Microbiology, University of Murcia) is gratefully acknowledged for the revision of the manuscript.

\section{REFERENCES}

Bhatt, A., Fujiwara, N., Bhatt, K., Gurcha, S. S., Kremer, L., Cheng, B., Chan, J., Porcelli, S. A., Kobayashi, K. \& other authors (2007). Deletion of kasB in Mycobacterium tuberculosis causes loss of acidfastness and subclinical latent tuberculosis in immunocompetent mice. Proc Natl Acad Sci U S A 104, 5157-5162.

Bloch, H. (1950). Studies on the virulence of tubercle bacilli. Isolation and biological properties of a constituent of virulent organisms. J Exp Med 91, 197-218.

Bowdish, D. M. E., Sakamoto, K., Kim, M.-J., Mariliis Kroos, M., Mukhopadhyay, S., Leifer, C. A., Tryggvason, K., Gordon, S. \& Russell, D. G. (2009). MARCO, TLR2, and CD14 are required for macrophage cytokine responses to mycobacterial trehalose dimycolate and Mycobacterium tuberculosis. PLoS Pathog 5, e1000474.

Brennan, P. J. \& Nikaido, H. (1995). The envelope of mycobacteria. Аnпu Rev Biochem 64, 29-63.
Cooper, A. M. (2009). Cell-mediated immune responses in tuberculosis. Annu Rev Immunol 27, 393-422.

Daffé, M. \& Draper, P. (1998). The envelope layers of mycobacteria with reference to their pathogenicity. Adv Microb Physiol 39, 131203.

Dao, D. N., Sweeney, K., Hsu, T., Gurcha, S. S., Nascimento, I. P., Roshevsky, D., Besra, G., Chan, J., Porcelli, S. A. \& Jacobs, W. R., Jr (2008). Mycolic acid modification by mmaA4 gene of M. tuberculosis modulates IL-12 production. PLoS Pathog 4, e1000081.

Dietrich, J. \& Doherty, T. M. (2009). Interaction of Mycobacterium tuberculosis with the host: consequences for vaccine development. APMIS 117, 440-457.

Divya Jyothi, M., Garg, S. K. \& Singh, N. B. (2000). Mechanisms involved in protective immune response generated by secretory proteins of Mycobacterium habana against experimental tuberculosis. Scand J Immunol 51, 502-510.

Dubnau, E., Chan, J., Raynaud, C., Mohan, V. P., Laneélle, M. A., Yu, K., Quémard, A., Smith, I. \& Daffé, M. (2000). Oxygenated mycolic acids are necessary for virulence of Mycobacterium tuberculosis in mice. Mol Microbiol 36, 630-637.

Falkinham, J. O., III (1996). Epidemiology of infection by nontuberculous mycobacteria. Clin Microbiol Rev 9, 177-215.

Fujita, Y., Naka, T., McNeil, M. R. \& Yano, I. (2005). Intact molecular characterization of cord factor (trehalose 6,6'-dimycolate) from nine species of mycobacteria by MALDI-TOF mass spectrometry. Microbiology 151, 3403-3416.

Fujita, Y., Okamoto, Y., Uenishi, Y., Sunagawa, M., Uchiyama, T. \& Yano, I. (2007). Molecular and supramolecular structure related differences in toxicity and granulomatogenic activity of mycobacterial cord factor in mice. Microb Pathog 43, 10-21.

Glickman, M. S., Cox, J. S. \& Jacobs, W. R., Jr (2000). A novel mycolic acid cyclopropane synthetase is required for cording, persistence, and virulence of Mycobacterium tuberculosis. Mol Cell 5, 717-727.

Gupta, H. P., Singh, N. B., Mathur, I. S. \& Gupta, S. K. (1979). Mycobacterium habana, a new immunogenic strain in experimental tuberculosis. Indian J Exp Biol 17, 1190-1193.

Hayashi, D., Takii, T., Fujiwara, N., Fujita, Y., Yano, I., Yamamoto, S., Kondo, M., Inagaki, M., Yasuda, E. \& other authors (2009). Comparable studies of immunostimulating activities in vitro among Mycobacterium bovis Bacillus Calmette-Guérin (BCG) substrains. FEMS Immunol Med Microbiol 56, 116-128.

Hunter, R. L., Olsen, M. R., Jagannath, C. \& Actor, J. K. (2006). Multiple roles of cord factor in the pathogenesis of primary, secondary, and cavitary tuberculosis, including a revised description of the pathology of secondary disease. Ann Clin Lab Sci 36, 371386.

Hunter, R. L., Armitige, L., Jagannath, C. \& Actor, J. K. (2009). TB research at UT-Houston. A review of cord factor: new approaches to drugs, vaccines and the pathogenesis of tuberculosis. Tuberculosis (Edinb) 89, S18-S25.

Ishikawa, E., Ishikawa, T., Morita, Y. S., Toyonaga, K., Yamada, H., Takeuchi, O., Kinoshita, T., Akira, S., Yoshikai, Y. \& Yamashaki, S. (2009). Direct recognition of the mycobacterial glycolipid, trehalose dimycolate, by C-type lectin Mincle. J Exp Med 206, 2879-2888.

Khoo, K. H., Chaterjee, D., Dell, A., Morris, H. R., Brennan, P. J. \& Draper, P. (1996). Novel O-methylated terminal glucuronic acid characterizes the polar glycopeptidolipids of Mycobacterium habana TMC 5135. J Biol Chem 271, 12333-12342.

Lin, F. L., van Halbeek, H. \& Bertozzi, C. R. (2007). Synthesis of mono- and dideoxygenated $\alpha, \alpha$-trehalose analogs. Carbohydr Res 342, 2014-2030. 
McNeil, M., Daffé, M. \& Brennan, P. J. (1991). Location of mycoloyl ester substituents in the cell walls of mycobacteria. J Biol Chem $\mathbf{2 6 6}$ 13217-13223.

Mederos, L. M., Gutiérrez, A. M. \& Valdivia, J. A. (1992). Utilization of a new culture medium in biochemical tests for the mycobacterial classification. Mem Inst Oswaldo Cruz 87, 441.

Mederos, L. M., Valdivia, J. A. \& Valero-Guillén, P. L. (1998). Analysis of lipids reveals differences between 'Mycobacterium habana' and Mycobacterium simiae. Microbiology 144, 1181-1188.

Mederos, L. M., Valdivia, J. A. \& Valero-Guillén, P. L. (2006). Lipids of 'Mycobacterium habana', a synonym of Mycobacterium simiae with vaccine potential. Tuberculosis (Edinb) 86, 324-329.

Mederos, L., Valdivia, J. A. \& Valero-Guillén, P. L. (2007). Analysis of the structure of mycolic acids of Mycobacterium simiae reveals a particular composition of $\alpha$-mycolates in strain 'habana' TMC 5135, considered as immunogenic in tuberculosis and leprosy. Microbiology 153, 4159-4165.

Mederos, L., Valdivia, J. A. \& Valero-Guillén, P. L. (2008). New variants of polar glycopeptidolipids detected in Mycobacterium simiae, including 'habana' strains, as evidenced by electrospray ionizationion trap-mass spectrometry. J Appl Microbiol 105, 602-614.

Minnikin, D. E. (1982). Lipids: complex lipids. In The Biology of the Mycobacteria, vol. 1, pp. 95-184. Edited by C. Ratledge \& J. L. Stanford. London: Academic Press.

Minnikin, D. E. \& Goodfellow, M. (1976). Lipid composition in the classification and identification of nocardiae and related taxa. In The Biology of the Nocardiae, pp. 160-219. Edited by M. Goodfellow, G. H. Brownell \& J. A. Serrano. London: Academic Press.

Niescher, S., Wray, V., Lang, S., Kaschabek, S. R. \& Schlömann, M. (2006). Identification and structural characterisation of novel trehalose dinocardomycolates from $n$-alkane-grown Rhodococcus opacus 1CP. Appl Microbiol Biotechnol 70, 605-611.

Nishizawa, M., Yamamoto, H., Imagawa, H., Barbier-Chassafière, V., Petit, M., Azuma, I. \& Papy-Garcia, D. (2007). Efficient synthesis of a series of trehalose dimycolate (TDM)/trehalose dicorynemycolate (TDCM) analogues and their interleukin-6 level enhancement activity in mice sera. J Org Chem 72, 1627-1633.

Noll, H., Bloch, H., Asselineau, J. \& Lederer, E. (1956). The chemical structure of the cord factor of Mycobacterium tuberculosis. Biochim Biophys Acta 20, 299-309.

Ozeki, Y., Tsutsui, H., Kawada, N., Suzuki, H., Kataoka, M., Kodama, T., Yano, I., Kaneda, K. \& Kobayashi, K. (2006). Macrophage scavenger receptor down-regulates mycobacterial cord factor-induced proinflammatory cytokine production by alveolar and hepatic macrophages. Microb Pathog 40, 171-176.

Quémard, A., Lanéelle, M. A., Marrackhi, H., Promé, D., Dubnau, E. \& Daffé, M. (1997). Structure of a hydroxymycolic acid potentially involved in the synthesis of oxygenated mycolic acids of Mycobacterium tuberculosis complex. Eur J Biochem 250, 758-763.

Rao, V., Fujiwara, N., Porcelli, S. A. \& Glickman, M. S. (2005). Mycobacterium tuberculosis controls host innate immune activation through cyclopropane modification of a glycolipid effector molecule. J Exp Med 201, 535-543.

Rao, V., Gao, F., Chen, B., Jacobs, W. R., Jr \& Glickman, M. S. (2006). Trans-cyclopropanation of mycolic acids on trehalose dimycolate suppresses Mycobacterium tuberculosis-induced inflammation and virulence. J Clin Invest 116, 1660-1667.

Rhoades, E., Hsu, F. F., Torrelles, J. B., Turk, J., Chaterjee, D. \& Russell, D. G. (2003). Identification and macrophage-activating activity of glycolipids released from intracellular Mycobacterium bovis BCG. Mol Microbiol 48, 875-888.

Riley, L. W. (2006). Of mice, men, and elephants: Mycobacterium tuberculosis cell envelope and pathogenesis. J Clin Invest 116, 1475-1478.
Schroeder, B. G. \& Barry, C. E. (2001). The specificity of methyl transferases involved in trans mycolic acid biosynthesis in Mycobacterium tuberculosis and Mycobacterium smegmatis. Bioorg Chem 29, 164-177.

Silva, C. L., Tincani, I., Brandao-Filho, S. L. \& Faccioli, L. H. (1988). Mouse cachexia induced by trehalose dimycolate from Nocardia asteroides. J Gen Microbiol 134, 1629-1633.

Singh, N. B., Lowe, C. R. E., Rees, R. J. W. \& Colston, M. J. (1989). Vaccination of mice against Mycobacterium leprae infection. Infect Immun 57, 653-655.

Singh, N. B., Gupta, H. P., Srivastava, A., Kandpal, H. \& Srivastava, U. M. (1997). Lymphostimulatory and delayed-type hypersensitivity responses to a candidate leprosy vaccine strain: Mycobacterium habana. Lepr Rev 68, 125-130.

Takayama, K., Wang, C. \& Besra, G. S. (2005). Pathway to synthesis and processing of mycolic acids in Mycobacterium tuberculosis. Clin Microbiol Rev 18, 81-101.

Takimoto, H., Maruyama, H., Shimada, K.-L., Yakabe, R., Yano, I. \& Kumazawa, Y. (2006). Interferon- $\gamma$ independent formation of pulmonary granuloma in mice by injections with trehalose dimycolate (cord factor), lipoarabinomannan and phosphatidylinositol mannosides isolated from Mycobacterium tuberculosis. Clin Exp Immunol 144, 134-141.

Ueda, S., Fujiwara, N., Naka, T., Sakaguchi, I., Ozeki, Y., Yano, I., Kasama, T. \& Kobayashi, K. (2001). Structure-activity relationship of mycoloyl glycolipids derived from Rhodococcus sp. 4306. Microb Pathog 30, 91-99.

Valdivia, J. A. (1973). Mycobacterium habana: clinical and epidemiological significance. Ann Soc Belg Med Trop 53, 263-266.

Villeneuve, M., Kawai, M., Watanabe, M., Aoyagi, I., Hitotsuyanagi, Y., Takeya, K., Gouda, H., Hirono, S., Minnikin, D. E. \& Nakahara, H. (2007). Conformational behavior of oxygenated mycobacterial mycolic acids from Mycobacterium bovis BCG. Biochim Biophys Acta 1768, 1717-1726.

Villeneuve, M., Kawai, M., Watanabe, M., Aoyagi, I., Hitotsuyanagi, Y., Takeya, K., Gouda, H., Hirono, S., Minnikin, D. E. \& Nakahara, H. (2010). Differential conformational behaviors of $\alpha$-mycolic acids in Langmuir monolayers and computer simulation. Chem Phys Lipids 163, 569-579.

Watanabe, M., Ohta, A., Sasaki, A. \& Minnikin, D. E. (1999). Structure of a new glycolipid from the Mycobacterium avium-Mycobacterium intracellulare complex. J Bacteriol 181, 2293-2297.

Watanabe, M., Aoyagi, Y., Ridell, M. \& Minnikin, D. E. (2001). Separation and characterization of individual mycolic acids in representative mycobacteria. Microbiology 147, 1825-1837.

Watanabe, M., Aoyagi, Y., Mitome, H., Fujita, T., Naoki, H., Ridell, M. \& Minnikin, D. E. (2002). Location of functional groups in mycobacterial meromycolate chains; the recognition of new structural principles in mycolic acids. Microbiology 148, 1881-1902.

Weiszfeiler, J. G. \& Karczag, E. (1976). Synonymy of Mycobacterium simiae Karasseva et al. 1965 and Mycobacterium habana Valdivia et al. 1971. Int J Syst Bacteriol 26, 474-477.

Welsh, K. J., Abbott, A. N., Hwang, S.-A., Indrigo, J., Armitige, L. Y., Blackburn, M. R., Hunter, R. L., Jr \& Actor, J. K. (2008). A role for tumour necrosis factor- $\alpha$, complement $\mathrm{C} 5$ and interleukin- 6 in the initiation and development of the mycobacterial cord factor trehalose 6,6'-dimycolate induced granulomatous response. Microbiology 154, 1813-1824.

Werninghaus, K., Babiak, A., Groß, O., Hölscher, C., Dietrich, H., Agger, E. M., Mages, J., Mocsai, A., Schoenen, H. \& other authors (2009). Adjuvanticity of a synthetic cord factor analogue for subunit Mycobacterium tuberculosis vaccination requires FcR $\gamma$-Syk-Card9dependent innate immune activation. J Exp Med 206, 89-97.

Edited by: M. Daffé 